\title{
Simple, Directional cDNA Cloning for In Situ Transcript Hybridization Screens
}

BioTechniques 31:938-946(October 2001)

\author{
R. Tamme, K. Mills, \\ B. Rainbird, S. Nornes, and \\ M. Lardelli \\ The University of Adelaide, \\ Adelaide, Australia
}

situ transcript hybridization screening. In the former strategy, mutations are generated at random in an organism's genome, and then the progeny of the organism are analyzed for developmental defects (7). The mutated genes are then cloned by positional techniques or, if an insertional mutagenesis system has been used, by isolation of the sequences flanking the insert (1). Screening by in situ transcript hybridization is based on the observation that genes controlling development are often expressed in restricted patterns that reflect their developmental function. In this strategy, cDNAs from a relevant tissue or developmental stage are used to produce antisense probes. The genes corresponding to these probes are then tested by in situ hybridization to reveal if they are transcribed in spatiotemporal patterns implicative of a developmental role (13). Unlike mutational screening, in situ screens do not immediately demonstrate a developmental role for a gene. However, they do allow the im mediate identification of candidate developmental control genes. Also, in situ screens do not require the time-consuming and expensive breeding programs of mutation screens.

The hybridization of whole em bryos/tissues (i.e., whole-mount) with digoxigenin (DIG)-labeled antisense RNA probes (riboprobes) is currently the most specific, sensitive, and informative method of in situ transcript hybridization. However, the cost-effective synthesis of antisense riboprobes requires the orientation of the template cDNA to be known-otherwise, probes synthesized from both cDNA strands must be tested. For this reason, directionally cloned cDNA libraries are used for in situ screening. This requirement can present difficulties. For example, directional cloning of cDNA is com monly performed using a poly(dT) oligonucleotide that primes reverse transcription by hybridizing with the terminal poly(A) tail of transcripts. However, the transcripts of some model organisms, notably the zebrafish Danio rerio, commonly have long ( $\geq 1 \mathrm{~kb}) 3^{\prime}$ untranslated regions (UTRs) (see Results and Discussion). Thus, poly(dT)primed cDNA clones may not extend into the open reading frame to allow the identification of the protein product of genes identified to be of interest. This problem may be overcome by the synthesis of long cDNAs (>4 kb), but riboprobes produced from these are not optimal for in situ transcript hybridization (8). The use of randomly primed, directionally cloned cDNA libraries can alleviate this problem. However, their production is not trivial and commonly requires microgram quantities of mRNA, which may be difficult to obtain when the tissue of interest is not plentiful.

RT-PCR-based methods are valuable for the synthesis of cDNA from small quantities of mRNA. However, when used for the construction of cDNA libraries, these methods rely on poly(dT) priming for first-strand synthesis and the addition (usually by ligation) of an upstream second primer binding site to allow second-strand synthesis. This latter step is also not trivial.

In this paper, we describe novel procedures for the synthesis and directional cloning of randomly primed cDNA from small quantities of embryonic zebrafish material. We also describe a method for efficient antisense riboprobe synthesis from randomly selected clones, followed by whole-mount in situ transcript hybridization screening to find candidate developmental control genes. The results from the trials of these procedures are presented. 


\section{MATERIALS AND METHODS}

\section{Randomly Primed Directional cDNA Synthesis}

mRNA purification. mRNA is purified from the zebrafish embryos at the desired developmental stage on oligo(dT)-coated magnetic particles using the Dynabeads ${ }^{\circledR}$ mRNA Direct ${ }^{\mathrm{TM}}$ Kit, according to the manufacturer's instructions (Dynal AS, Oslo, Norway).

\section{Reverse Transcription (cDNA First- Strand Synthesis)}

To prime reverse transcription, we use a $5^{\prime}$-biotinylated oligonucleotide (RT-primer) possessing a degenerate $3^{\prime}$ end (i.e., A,C,G, or T at any of the eight 3 '-most bases), an internal PCR primer complementary region, and Not I and XhoI restriction sites (Figure 1, and Table 1). The primer is bound to streptavidin-coated magnetic beads (Dynabeads M-280 Streptavidin; Dynal). Thirty microliters $(300 \mu \mathrm{g})$ magnetic beads are prewashed to prepare them for RNase-free work, as described by the manufacturer. The beads are resuspended in $40-50 \mu \mathrm{L}$ binding buffer containing $1 \mathrm{M} \mathrm{NaCl}, 10 \mathrm{mM}$ Tris- $\mathrm{HCl}$, pH 8.0, 1 mM EDTA (Sigma) in a 1.5$\mathrm{mL}$ microcentrifuge tube, before the addition of $1 \mu \mathrm{L} 60 \mu \mathrm{M}$ RT-primer. The mixture is incubated at room temperature for 40-60 min, with continuous rotation to hold the beads in suspension. Unbound RT-primer is removed by rinsing the beads once in $50 \mu \mathrm{L}$ binding buffer and twice in $50 \mu \mathrm{L}$ distilled water. A volume $(17 \mu \mathrm{L})$ containing 200-400 ng mRNA is then used to resuspend the beads. (Lesser amounts of mRNA can also be used.) The suspension is incubated at $70^{\circ} \mathrm{C}$ for $10 \mathrm{~min}$ before rapid chilling on ice, followed by the addition of $1 \mu \mathrm{L}(1 \mathrm{U} / \mu \mathrm{L})$ RNase inhibitor (Fermentas AB, Vilnius, Lithuania). The following reagents for reverse transcription are added: $8 \mu \mathrm{L}$ $5 \times$ first-strand buffer $(250 \mathrm{mM}$ Tris$\mathrm{HCl}, \mathrm{pH} 8.3,375 \mathrm{mM} \mathrm{KCl}, 15 \mathrm{mM}$ $\left.\mathrm{MgCl}_{2}\right), 4 \mu \mathrm{L} 0.1 \mathrm{mM}$ DTT, and $8.5 \mu \mathrm{L}$ of a solution containing $2.5 \mathrm{mM}$ each of dATP, dCTP, dGTP, and dTTP. This is followed by the addition of $2.5 \mu \mathrm{L}$ SUPERSCRIPT IITM RT RNAse H Reverse Transcriptase (Invitrogen, Carls- bad, CA, USA) to produce a final volume of $40 \mu \mathrm{L}$. The reaction is then incubated for $2 \mathrm{~h}$ at $37^{\circ} \mathrm{C}$ with continuous rotation.

\section{Removal of the RNA Template}

Sixty microliters of solution containing $0.21 \mathrm{M} \mathrm{NaOH}$ and $0.1 \mathrm{M} \mathrm{NaCl}$ is added to the reverse transcription reaction and incubated for $30 \mathrm{~s}$ at room tem perature. This solution is removed, and the beads are rinsed immediatelyonce in $100 \mu \mathrm{L} 0.15 \mathrm{M} \mathrm{NaOH}$ and 0.1 $\mathrm{M} \mathrm{NaCl}$, once in $100 \mu \mathrm{L} 1 \mathrm{M} \mathrm{NaCl}$ and $0.5 \mathrm{M}$ Tris- $\mathrm{HCl}, \mathrm{pH} 7.0$, and then twice in $100 \mu \mathrm{L}$ distilled water. The beads are then resuspended in $100 \mu \mathrm{L}$ distilled water and stored at $-20^{\circ} \mathrm{C}$ until use.

\section{Synthesis of the Second cDNA Strand and PCR amplification}

The synthesis of the second cDNA strand exploits the phenomenon of nonspecific binding of oligonucleotides on DNA templates at low temperatures. This phenomenon has been used in a number of circumstances to prime reactions in regions of unknown DNA sequence $(4,12,14,15,17,18)$. In the following procedure, the priming of the second cDNA strand is performed by a non-degenerate 2 nd primer that binds nonspecifically to the first-strand tem plate (Figure 1, and Table 1). The 2nd primer is identical to part of the RTprimer and includes the XhoI site of RTprimer. Thus, once it has primed synthesis of the second cDNA strand to form a

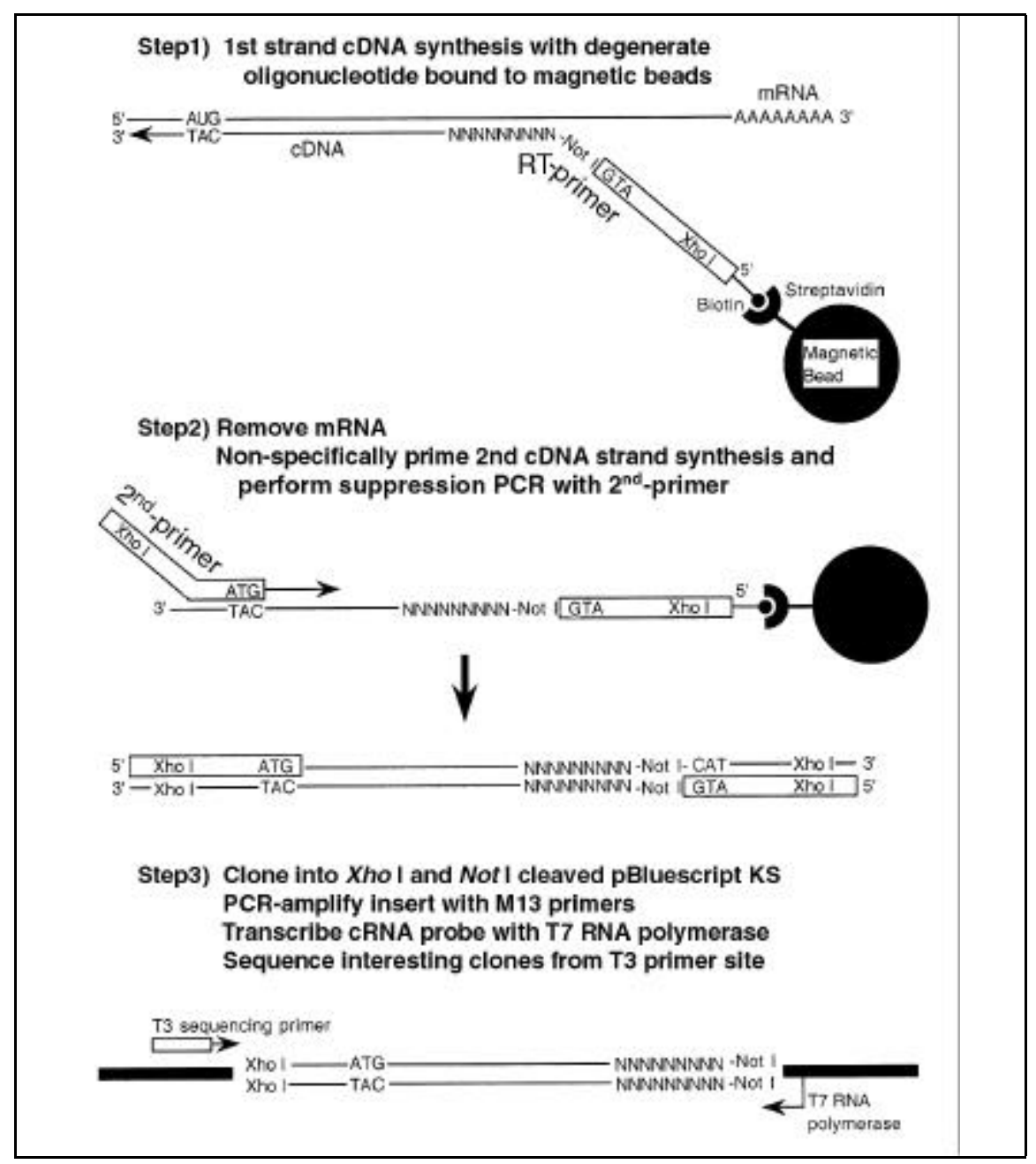

Figure 1. Diagram of the suppression PCR-based method for generation of directionally cloned cDNAs from small quantities of mRNA. The boxed areas in Step 1 and Step 2 represent the 2nd primer or homology with the 2nd primer. The ATG at the $3^{\prime}$ end of the 2nd primer may assist in the priming of PCR from the start of open reading frames but does not restrict priming to these areas. 


\section{Research Report}

Table 1. Sequences of Primers Used for cDNA Synthesis

\begin{tabular}{|ll|}
\hline Name & Sequence \\
\hline RT-primer & 5' biotin-TATACCGCCTCGAGCGTCCACCATGTAGCGGCCGCNNNNNNNN-3' \\
2nd primer & 5'-CCGCCTCGAGCGTCCACCATG-3' \\
\hline
\end{tabular}

double helix, the 2 nd primer can then be used in PCR (i.e., it can prime DNA synthesis at both ends of the cDNA fragment using a raised, specific annealing temperature). Consequently, the am plified fragment has inverted repeats at both ends corresponding to the 2nd primer. The ends of each single DNA strand are complementary and can therefore anneal. During PCR, annealing of single-strand ends competes with their annealing to the 2nd primer. This suppresses DNA synthesis if strand lengths are short or primer concentrations are low. This suppression effect (suppression PCR) (11) counteracts the tendency of PCR to selectively amplify shorter DNA fragments-something that would otherwise be a problem because of the initial nonspecific priming by the 2 nd primer.

Twenty microliters (1/5) of the resuspended beads possessing bound firststrand cDNA are placed in a total volume of $50 \mu \mathrm{L}$ PCR buffer containing 10 mM Tris-HCl, pH 9.0 (Sigma, St. Louis, MO, USA), $50 \mathrm{mM} \mathrm{KCl,} 15 \mathrm{mM}$ $\mathrm{MgCl}_{2}, 0.1 \%$ Triton $^{\circledR} \mathrm{X}-100$ (Sigma), and $0.2 \mathrm{mM}$ each dATP, dCTP, dGTP, and dTTP (Amersham Pharmacia Biotech AB, Uppsala, Sweden), 0.2 $\mu \mathrm{M}$ 2nd primer, and $1 \mathrm{U}$ recombinant DyNAzyme $^{\mathrm{TM}}$ Thermostable DNA Polymerase (Finnzymes Oy, Espoo, Finland). The reaction is covered in paraffin oil and subjected to the following tem perature cycling for the synthesis of the second cDNA strand: $94^{\circ} \mathrm{C}$ for $40 \mathrm{~s}$, then 5 cycles of $25^{\circ} \mathrm{C}$ for $2 \mathrm{~min}$, ramp of $1{ }^{\circ} \mathrm{C} / \mathrm{s}$ up to $72^{\circ} \mathrm{C}, 72^{\circ} \mathrm{C}$ for $5 \mathrm{~min}$. During these first five cycles, the beads are resuspended once during each primer annealing and DNA-strand elongation step by placing a $20-\mu \mathrm{L}$ micropipette tip through the oil layer and pipetting a 10 $\mu \mathrm{L}$ volume rapidly up and down a num ber of times. Also note that the secondstrand synthesis products are not denatured from first-strand cDNA molecules during these cycles. Thus, nonspecific priming by the 2 nd primer can only occur on naked first-strand cDNA tem plates and not on second-strand cDNA. The second-strand synthesis cycles then lead directly into $30 \mathrm{PCR}$ cycles of $94^{\circ} \mathrm{C}$ for $40 \mathrm{~s}, 60^{\circ} \mathrm{C}$ for $40 \mathrm{~s}$, ramp of $0.5^{\circ} \mathrm{C} / \mathrm{s}$ up to $72^{\circ} \mathrm{C}, 72^{\circ} \mathrm{C}$ for $5 \mathrm{~min}$. During the first five cycles, the beads are resuspended during each elongation step.

\section{Size Selection of cDNA and Directional Cloning}

After PCR, the enzyme, oligonucleotides, and salts are removed from the reaction using the Wizard ${ }^{\circledR}$ PCR Preps DNA Purification System (Promega, Madison, WI, USA). The DNA is recovered in $40 \mu \mathrm{L}$ distilled water and then digested with NotI and XhoI (Fermentas) before electophoresis alongside DNA size markers (1 kb ladder; Invitrogen) on a $1 \% \mathrm{w} / \mathrm{v}$ low melting temperature agarose gel (SeaPlaque ${ }^{\circledR}$; BMA, Rockland, ME, USA) in Tris acetate EDTA (TAE) buffer (16) containing 10 $\mathrm{mg} / \mathrm{mL}$ ethidium bromide (Sigma). A region of the gel containing cDNA ranging from $0.5-2.0 \mathrm{~kb}$ in length is excised under long-wave UV illumination. The DNA is purified from this using the Wizard PCR Preps DNA Purification System. The DNA is ligated with pBluescript ${ }^{\circledR} \mathrm{II} \mathrm{KS}+$ plasmid vector (Stratagene, La Jolla, CA, USA) that has been restricted with NotI and XhoI and purified after excision from a low melting temperature agarose gel as described above. The ligation products are transformed by electroporation into $E$. coli strain DH5 $\alpha$ and plated onto L-agar containing $50 \mu \mathrm{g} / \mathrm{mL}$ ampicillin (Sigma). Colonies are picked and restreaked onto fresh plates. To examine the size of individual cDNA clones, a sample of each colony is then lysed at $95^{\circ} \mathrm{C}$ for 5 min in $30 \mu \mathrm{L}$ PCR buffer lacking $\mathrm{MgCl}_{2}$ (under paraffin oil). The lysates $(2 \mu \mathrm{L})$ are used in $25 \mu \mathrm{L}$ reactions under the reaction solution conditions described above, but using the "M13 reverse" and "M13-20" oligonucleotide primers (Stratagene) that flank the cloning region of the vector. Cycling is
35 cycles of $94^{\circ} \mathrm{C}$ for $40 \mathrm{~s}, 52^{\circ} \mathrm{C}$ for 40 $\mathrm{s}$, ramp of $0.5^{\circ} \mathrm{C} / \mathrm{s}$ to $72^{\circ} \mathrm{C}, 72^{\circ} \mathrm{C}$ for 3 min. Note that colonies can be picked directly and lysed for PCR, but restreaking gives more reliable results. Reactions containing cDNA fragments ranging from $0.5-2.0 \mathrm{~kb}$ are identified by electrophoresis of samples of each reaction against size markers on a $1.25 \%$ w/v agarose gel in TAE buffer. These are then stored at $-70^{\circ} \mathrm{C}$ for later use in sequencing and making riboprobes.

\section{Sequence Analysis of cDNAs}

M13 primer PCRs are passed over 1mL Sephacryl ${ }^{\circledR}$ S-400 HR (Amersham Pharmacia Biotech) columns before we sequence the products using the T3 primer (Stratagene) with ABI PRISM ${ }^{\circledR}$ BigDye ${ }^{\circledR}$ fluorescent dye terminators (Applied Biosystems, Foster City, CA, USA). Sequencing reaction products are analyzed on an ABI PRISM 373 sequencer (Applied Biosystems).

\section{Riboprobe Synthesis}

One to six microliters containing 100-200 ng amplified insert from the M13 primer PCRs are used directly in $10 \mu \mathrm{L}$ riboprobe reactions. Each reaction contains $20 \mathrm{U}$ T7 RNA polymerase and $1 \mathrm{U}$ ribonuclease inhibitor (Fermentas) in $40 \mathrm{mM}$ Tris- $\mathrm{HCl}, \mathrm{pH} 8.0,6 \mathrm{mM}$ $\mathrm{MgCl}_{2}, 10 \mathrm{mM}$ DTT, $10 \mathrm{mM} \mathrm{NaCl}, 2$ $\mathrm{mM}$ spermidine with $0.5 \mathrm{mM}$ each ATP, GTP, CTP, 0.32 mM UTP (Amersham Pharmacia Biotech), and $1.7 \mathrm{mM}$ Digoxigenin-11-UTP (Roche Diagnostics, Penzberg, Germany). The riboprobes are purified by dilution to $500 \mu \mathrm{L}$ with water and then by filtration over 30 K Nanosep ${ }^{\mathrm{TM}}$ devices (Pall Gelman Sciences, Ann Arbor, MI, USA) at 5000× $g$ for $12 \mathrm{~min}$. This step is followed by the rinsing of the retentate with $400 \mu \mathrm{L}$ of $10 \mathrm{mM}$ Tris-HCl, pH 7.5, $0.5 \mathrm{mM}$ EDTA solution, then the repetition of the centrifugation followed by the recovery of the riboprobe using two $20-\mu \mathrm{L}$ rinses of the device's membrane with water. 


\section{Whole-Mount In Situ Transcript Hybridization}

Zebrafish embryos up to $24 \mathrm{~h}$ post fertilization (hpf) are dechorionated manually or with protease from Streptomyces griseus (Sigma) and fixed at $4{ }^{\circ} \mathrm{C}$ overnight in $4 \%$ formaldehyde in PBS solution. The embryos are rinsed in, then incubated overnight in, $100 \%$ methanol at $-20^{\circ} \mathrm{C}$ before rehydration through a methanol/PBS series (5-min washes each in $75 \%, 50 \%, 25 \%$ $\mathrm{MeOH})$ and washing $4 \times 5 \mathrm{~min}$ in PBS $+0.1 \%$ Tween $^{\circledR} 20$ (PBT). Embryos are transferred to 1.5-mL Safe-Lock ${ }^{\mathrm{TM}} \mathrm{mi}-$ crotest tubes with locking caps (Eppendorf Netheler Hinz GmbH, Hamburg, Germany) and rinsed once in $1 \mathrm{~mL}$ prehybridization buffer (PHB) containing $50 \%$ formamide (deionized over $A_{G^{\circledR}}$ 501-X8(D) resin; Bio-Rad Laboratories, Hercules, CA, USA), $5 \times \mathrm{SSC}$ (150 mM NaCl, $15 \mathrm{mM}$ sodium citrate,
pH 7.0), 2\% blocking reagent (Roche Diagnostics), $0.1 \%$ Tween 20, $0.5 \%$ CHAPS (both from Sigma), $50 \mu \mathrm{g} / \mathrm{mL}$ yeast RNA (Roche Diagnostics), $5 \mathrm{mM}$ EDTA, and $50 \mu \mathrm{g} / \mathrm{mL}$ heparin (Sigma). The embryos are incubated in $1 \mathrm{~mL}$ $\mathrm{PHB}$ in a horizontal position with slow rocking for $1 \mathrm{~h}$ at $70^{\circ} \mathrm{C}$. Probe solution (200-300 $\mathrm{ng}$ ) is then added to each tube and mixed into the PHB before incubation overnight at $70^{\circ} \mathrm{C}$.

The next day, the embryos are rinsed with $3 \times 1 \mathrm{~mL} \mathrm{PHB}$ at $70^{\circ} \mathrm{C}$ and then washed for $2 \times 15 \mathrm{~min}$ in $\mathrm{PHB}$ at $70^{\circ} \mathrm{C}$. Embryos are then washed for $1 \times 30 \mathrm{~min}$ in a solution consisting of $50 \%$ $\mathrm{PHB} / 50 \% 2 \times \mathrm{SSCT}(\mathrm{SSC}+0.1 \%$ Tween 20 ), followed by $2 \times 3$ min washes in $300 \mu \mathrm{L} 50 \%$ deionized formamide $/ 50 \% 2 \times \mathrm{SSCT}$. The embryos are transferred to Netwell ${ }^{\mathrm{TM}}$ sieves (74$\mu \mathrm{m}$ mesh, 15-mm diameter; Corning Costar, Acton, MA, USA) in their microtiter trays containing $75 \mathrm{~mL} 2 \times$
SSCT prewarmed to $70^{\circ} \mathrm{C}$ in an oven. The embryos are incubated at $70^{\circ} \mathrm{C}$ for 15 min. Subsequent solution changes are performed by transferring sieves between Netwell reagent trays using the Netwell Carrier Kit (Corning Costar). Embryos are incubated for $2 \times 30-\mathrm{min}$ in $0.2 \times \mathrm{SSC}$ at $70^{\circ} \mathrm{C}$ and $2 \times 5 \mathrm{~min}$ in PBT at room temperature on a slowly oscillating shaker followed, by $1 \mathrm{~h}$ in PBT + 1\% BSA (Fraction V; Sigma) at room temperature. Each sieve is then transferred to a labeled position in a Netwell microtiter tray and incubated overnight at $4^{\circ} \mathrm{C}$ in $3 \mathrm{~mL}$ anti-DIG Fab fragments conjugated to alkaline phosphatase (Roche Diagnostics). The anti-DIG Fab fragments are diluted 1:5000 in PBT + $1 \%$ BSA at least $1 \mathrm{~h}$ before use.

The following day, the embryos in sieves are transferred to Netwell reagent trays for three rinses and then washing for $4 \times 30 \mathrm{~min}$ and $1 \times 60 \mathrm{~min}$ in PBT + $0.1 \%$ BSA. This is followed by rinsing 
once and washing $3 \times 5 \mathrm{~min}$ in NTMT buffer $(100 \mathrm{mM} \mathrm{NaCl}, 100 \mathrm{mM}$ Tris$\mathrm{HCl}$, pH 9.5, $50 \mathrm{mM} \mathrm{MgCl}_{2}, 0.1 \%$ Tween 20). Embryos are transferred to 2 $\mathrm{mL}$ capped glass vials for staining with gentle rocking in $1 \mathrm{~mL}$ NTMT buffer containing $0.34 \mathrm{mg}$ nitroblue tetrazolium chloride (NBT) and $0.175 \mathrm{mg} 5-$ Bromo-4-chloro-3-indolyl phosphate, toluidine salt (BCIP) (Roche Diagnostics). If no staining is visible after 30 min at room temperature, then staining is continued from $12 \mathrm{~h}$ to 4 days at $4^{\circ} \mathrm{C}$. After staining, embryos are rinsed in NTMT buffer, washed $1 \times 10 \mathrm{~min}$ in NTMT buffer, rinsed in PBT, washed 1 $\times 10 \mathrm{~min}$ in PBT, and then fixed in $4 \%$ formaldehyde in PBT overnight at $4^{\circ} \mathrm{C}$. The embryos are then equilibrated with $80 \%$ glycerol for observation. Photography of the embryos is conducted using differential interference contrast optics on an Axiophot ${ }^{\mathrm{TM}}$ microscope (Carl Zeiss Jena GmbH, Oberkochen, Germany). Images are assembled using
Adobe ${ }^{\circledR}$ Photoshop ${ }^{\circledR} 5.0$ software.

To control for correct performance, sensitivity, and levels of background, we always perform probe synthesis and in situ hybridization to detect transcription of the zebrafish notch6 gene using the clone BJ1 (19). This gene is expressed at low levels in presomitic mesoderm (sensitivity control), but is not expressed in the developing central nervous system (background control).

\section{Animal Ethics}

The work described in this paper was conducted under the auspices of the Animal Ethics Committee of The University of Adelaide.

\section{RESULTS AND DISCUSSION}

\section{Analysis of Clone Sequences}

mRNA was prepared from zebrafish embryos at 8-10 hpf. A randomly primed, directionally cloned library of cDNAs was produced as described in the Materials and Methods section.

The use of nonspecific priming in RT-PCR to amplify cDNAs might result in selective amplification of a limited number of clones. To test this, we picked clones at random and sequenced them at their upstream ends. Clones (66) were sequenced and then compared with each other using the fasta program (parameters at default values) (3) to detect identical clones. Seven of the 66 clones $(11 \%)$ were not unique. The largest number of copies of any one clone was three. The position of the binding sites of RT-primer on the mRNAs and 2nd primer on the cDNAs is expected to be largely random. Thus, these replicate clones are most probably copies arising from single priming events rather than independent events. For our purposes (performance of the in situ screen), the level of redundancy seen was deemed sufficiently low not to warrant attempts at normalization of the library. If this was not so, we could have used a PCRbased normalization method such as that of Kohchi et al. (9), which is based on single-strand reassociation kinetics.

Interestingly, among the 66 clones sequenced, one example was observed of clones derived from multiple prim ing sites on transcripts of the same gene. This, and the large number of unique sequences (presumably from separate genes) support the nonspecificity of the priming. In all, 61 unique sequences were obtained. The GenBank $^{\circledR}$ accession nos. for the 66 sequences are BF713834-67, BF72363060, and BG606066.

To reveal how many of the sequences represented transcripts that are already known from the zebrafish expressed sequence tag (EST) project, we searched GenBank's nrESTs database using the BLASTN $^{\circledR}$ program (http://www.ncbi.nlm.nih.gov/BLAST/; searches performed in June 2000). Of the 61 unique sequences, 28 (46\%) showed at least $96 \%$ identity over a minimum distance of 100 nucleotides (data not shown). As zebrafish EST sequences accumulate, the proportion of already identified sequences is expected to increase.

To gain some idea of how many of 


\begin{tabular}{|c|}
\hline Applied Biosys \\
$(6100)$ \\
$4 \mathrm{C}$ \\
\hline
\end{tabular}

Circle Reader Service No. 243 
the upstream sequences from the clones might represent open reading frames, we compared the clone sequences with those in GenBank's nrproteins database (http://www.ncbi.nlm.nih.gov/BLAST/) using the program BLASTX ${ }^{\circledR}$. Of the 61 sequences from separate genes, 21 $(34 \%)$ found alignments of greater than $50 \%$ putative amino acid residue identity over distances of at least 50 residues. These sequences presumably represent open reading frames. However, this is likely to be an underestimation because sequencing read errors and low levels of similarity to known proteins would be expected to reduce the number of detected alignments.

These results demonstrate that this PCR-based method for directional cloning of randomly primed cDNA represents a simple and effective method for cDNA cloning from small quantities of tissue. The use of random priming has allowed the cloning of a significant proportion of open reading frame sequences from an organism with transcripts that have, typically, long 3' UTRs. For exam ple, analysis of a random selection of 20 zebrafish mRNA sequences from GenBank showed an average 3' UTR length of 821 bases, and 11 of the 20 transcripts had 3' UTRs over 920-bases-long (data not shown). Apparently, the method does generate a proportion of redundant clones, primarily as a result of the PCR amplification. However, this method should prove useful in many cases in which the production of a normalized library is not essential.

\section{Use of the cDNA Clones in a Pilot in situ Screen}

Having established that the level of redundancy in our cDNA library was low enough for our purposes, we performed a pilot in situ transcript hybridization screen with 60 clones that were picked at random. These were not the same clones that were subjected to sequence analysis. In situ hybridization was performed on embryos fixed at 0 , $4,8,10,12,16$, and $24 \mathrm{hpf}$. Forty-one clones $(68 \%)$ revealed ubiquitous gene expression in embryos of all stages. Ten clones $(17 \%)$ revealed gene expression in restricted regions of embryos at some stage of development (Figure 2). A number of the clones re- vealing the most interesting gene expression patterns were subsequently sequenced (data not shown). This revealed that we had isolated clones for the previously described genes, spadetail (6) and tolloid (2), demonstrating the ability of our screening method to detect developmental control genes.

The remaining nine clones $(15 \%)$ did not give staining at any developmental stage, even after four days of incubation in staining solution. This could have been caused by a number of factors - contamination of the RT-PCR with non-transcribed genomic DNA sequences, an inability of the in situ transcript hybridization method to detect very low levels of transcription, or, sim ply, the failure to perform the in situ method correctly. To exclude the last alternative, we synthesized new probes and repeated the in situ hybridization for these clones. However, we were still unable to obtain any signal indicating

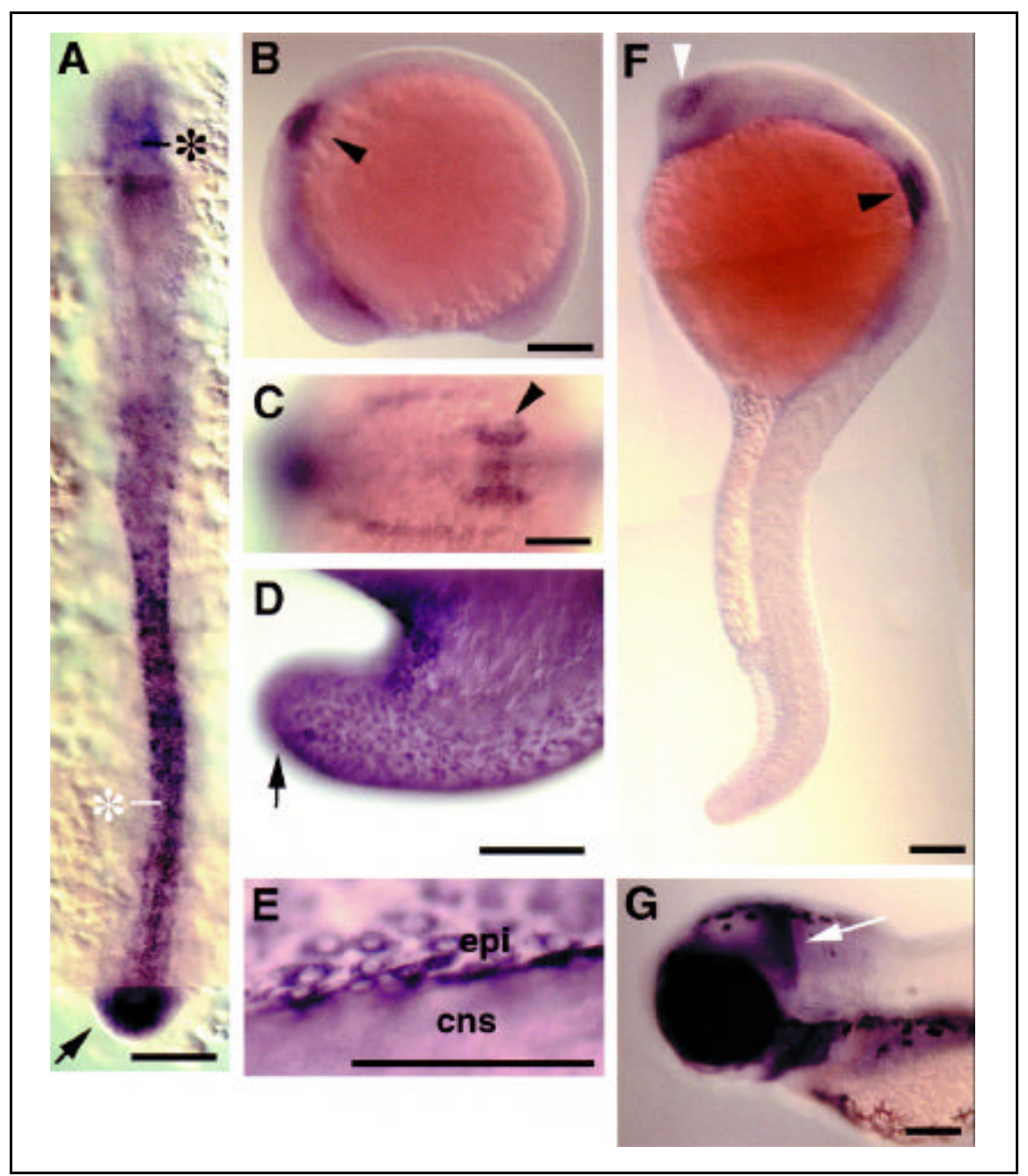

Figure 2. Examples of clones revealing restricted patterns of gene transcription during embryogenesis. Unless otherwise stated, anterior is to the left and dorsal is uppermost. (A) Clone $218 \mathrm{~h}$, dorsal axial view (anterior uppermost) at $14.5 \mathrm{hpf}$. Note that cell expression along the length of the developing central nervous system (cns) (white asterisk) and in regions of the developing brain (black asterisk). Expression is also observed in the tail bud (black arrow). (B) Clone 156h, lateral view at $12 \mathrm{hpf}$. Note the expression in the otic vesicle (black arrowhead). (C) Dorsal axial view of otic vesicles in panel B. (D) Clone 152h lateral view (anterior uppermost) of tail bud at $17.5 \mathrm{hpf}$. Apparently, perinuclear mRNA is only expressed in the epidermal cell layer. This is demonstrated clearly in panel $\mathrm{E}$, in which an optical section though the epidermis (epi) and the developing central nervous system from a dorso-lateral aspect show that no transcription is evident basal to the epidermis. (F) Clone 210h, lateral view at $24 \mathrm{hpf}$, showing transcription in the olfactory bulb (white arrowhead) and otic vesicle. (G) Clone 146h, lateral view of head at $48 \mathrm{hpf}$, showing expression at the midbrain-hindbrain boundary (white arrow). Scale bars, $100 \mu \mathrm{m}$. 
transcription, while the control (see Materials and Methods) indicated that the procedure had been conducted correctly. To exclude the possibility that these clones represented genomic DNA contamination, we sequenced five of them from their upstream ends and searched the nrEST and nrprotein databases with the BLASTN and BLASTX programs, respectively, to find matches to known transcribed and/or translated regions. Two of the five clones showed strong similarity to known protein coding regions in other species, and one of the five was identical (apparently) to the noncoding region of a zebrafish EST (data not shown). The two remaining clones did not show any significant similarity to known sequences. However, it was possible to show by RT-PCR on mRNA from 6-9 hpf embryos that these two last clones represent transcribed sequences (data not shown). Thus, the $15 \%$ of in situ screen clones for which no gene expression could be detected represent sequences transcribed at levels below the detection threshold of the whole-mount in situ transcript hybridization technique. We could not find any research literature that has evaluated the concentration threshold for transcript detection in whole-mount in situ transcript hybridization on zebrafish embryos (or on the embryos of any other animal). How ever, notch6 gene transcription, which served as our control, could be detected within $24 \mathrm{~h}$ of staining, whereas staining with the probes that detected no signal was continued for four days. The notch genes of the chordates are not expressed at high levels - whole embryo transcript frequencies in the range of one in 105-106 are typical (Reference 10, and unpublished observations).

Interestingly, the proportions of clones representing genes with ubiquitous, restricted, or no apparent expression are similar to those observed by Gawantka et al. (5) in their in situ screen of cDNAs derived from neurula-stage Xenopus embryos. In a screen of 1765 cDNAs, these authors observed that $51 \%$ of the clones identified genes with ubiquitous expression, $26 \%$ identified genes with restricted expression, and no gene expression could be identified for $23 \%$ of clones. Sequence analysis of 16 of the clones that had revealed no ex- pression detected five clones with similarity to known sequences. Our pilot screen and the subsequent analysis of clones revealing no expression confirms that these clones represent transcripts expressed in the embryo at levels too low to be detected by the whole-mount in situ transcript hybridization technique. This demonstates that, despite the fact that PCR might be expected to selectively favor the amplification of $\mathrm{cD}$ NAs initially expressed at higher levels, we have been able to clone numerous cDNAs from transcripts present at very low levels. The similar proportions of clones revealing ubiquitous, restricted, or no apparent expression in our screen and that of Gawantka et al. support the validity of our cDNA cloning technique.

\section{ACKNOWLEDGMENTS}

This work was supported by funds from an ARC Small Grant and from the ARC Special Research Centre for the Molecular Genetics of Development.

\section{REFERENCES}

1.Amsterdam, A., S. Burgess, G. Golling, W. Chen, Z. Sun, K. Townsend, S. Farrington, M. Haldi et al. 1999. A large-scale insertional mutagenesis screen in zebrafish. Genes Dev. 13:2713-2724.

2.Blader, P., S. Rastegar, N. Fischer, and U. Strahle. 1997. Cleavage of the BMP-4 antagonist chordin by zebrafish tolloid. Science 278:1937-1940.

3.Devereux, J., P. Haeberli, and O. Smithies. 1984. A comprehensive set of sequence analysis programs for the VAX. Nucleic Acids Res. 12:387-395

4.Domínguez, O. and C. López-Larrea. 1994. Gene walking by unpredictably primed PCR. Nucleic Acids Res. 22:3247-3248.

5.Gawantka, V., N. Pollet, H. Delius, M. Vingron, R. Pfister, R. Nitsch, C. Blumenstock, and C. Niehrs. 1998. Gene expression screening in Xenopus identifies molecular pathways, predicts gene function and provides a global view of embryonic patterning. Mech. Dev. 77:95-141

6.Griffin, K.J.P., S.L. Amacher, C.B. Kimmel, and D. Kimelman. 1998. Molecular identification of spadetail: regulation of zebrafish trunk and tail mesoderm formation by T-box genes. Development 125:3379-3388.

7.Haffter, P., M. Granato, M. Brand, M.C. Mullins, M. Hammerschmidt, D.A. Kane, J. Odenthal, F.J.M. van Eeden et al. 1996. The identification of genes with unique and essential functions in the development of the zebrafish, Danio rerio. Development 123:1-36.
8.Jowett, T 1997. Tissue in situ hybridisation, p. 1-27. Methods in Animal Development. Wiley and Sons, New York.

9.Kohchi, T., K. Fujishige, and K. Ohyama. 1995. Construction of an equalized cDNA library from Arabidopsis thaliana. Plant J. 8:771-776.

10.Lardelli, M. and U. Lendahl. 1994. Generating bacteriophage $\lambda$ sublibraries enriched for rare clones. BioTechniques 16:420-422.

11.Lukyanov, K.A., G.A. Launer, V.S. Tarabykin, A.G. Zaraisky, and S.A. Lukyanov. 1995. Inverted terminal repeats permit the average length of amplified DNA fragments to be regulated during preparation of cDNA libraries by polymerase chain reaction. Anal. Biochem. 229:198-202.

12.Malo, M.S., K. Srivastava, J.M. Andresen, X.-N. Chen, J.R. Korenberg, and V.M. Ingram. 1994. Targeted gene walking by low stringency polymerase chain reaction: assignment of a putative human brain sodium channel gene (SCN3A) to chromosome 2q24-31 Proc. Natl. Acad. Sci. USA 91:2975-2979.

13.Niehrs, C. 1997. Gene-expression screens in vertebrate embryos: more than meets the eye. Genes Funct. 1:229-231.

14.Parker, J.D., P.S. Rabinovitch, and G.C. Burmer. 1991. Targeted gene walking polymerase chain reaction. Nucleic Acids Res. 19:3055-3060.

15.Parks, C.L., L.-S. Chang, and T. Shenk. 1991. A polymerase chain reaction mediated by a single primer: cloning of genomic sequences adjacent to a serotonin receptor protein coding region. Nucleic Acids Res. 19:7155-7160.

16.Sambrook, J., E.F. Fritsch, and T. Maniatis. 1989. Molecular Cloning: A Laboratory Manual, 2nd Ed. CSH Laboratory Press, Cold Spring Harbor, NY.

17.Tamme, R., E. Camp, R.D. Kortschak, and M. Lardelli. 2000. Nonspecific, nested suppression PCR method for isolation of unknown flanking DNA. BioTechniques 28:895902

18.Trueba, G.A. and R.C. Johnson. 1996. Random primed gene walking PCR: a simple procedure to retrieve nucleotide fragments adjacent to known DNA sequences. BioTechniques 21:20.

19. Westin, J. and M. Lardelli. 1997. Three novel Notch genes in zebrafish: implications for vertebrate Notch gene evolution and function. Dev. Genes Evol. 207:51-63.

Received 8 January 2001; accepted 1 May 2001.

\section{Address correspondence to:}

Dr. Michael Lardelli

Department of Molecular Biosciences and

Special Research Centre for the Molecular Genetics of Development

Discipline of Genetics

The University of Adelaide

5005, Australia.

e-mail:michael.lardelli@adelaide.edu.au 